\title{
A Study in Multistage Decision Making for Odisha State Avionic Infrastructure Development
}

\author{
L. Das ${ }^{1}$, Chittaranjan Mallick ${ }^{2 *}$ \\ ${ }^{1}$ Delhi Technological University, Delhi, India \\ ${ }^{2}$ Parala Maharaja College of Engineering, Berhampur, Odisha, India \\ Email: ${ }^{*}$ cmallick75@gmail.com
}

How to cite this paper: Das, L. and Mallick, C. (2020) A Study in Multistage Decision Making for Odisha State Avionic Infrastructure Development. American Journal of Operations Research, 10, 25-30. https://doi.org/10.4236/ajor.2020.102003

Received: October 31, 2019

Accepted: January 18, 2020

Published: January 21, 2020

Copyright () 2020 by author(s) and Scientific Research Publishing Inc. This work is licensed under the Creative Commons Attribution International License (CC BY 4.0).

http://creativecommons.org/licenses/by/4.0/ (c) (i) Open Access

\begin{abstract}
Multistage decision making is either under certainty or uncertainty data conditions. Expected monetary values' perfect information and monetary loss or gain at each stage of decision making are the research topics of a constrained decision making under risk. In the multistage decision making process, one stage's decision interferes with the subsequent stage's decision. In this paper, a simple study on decision making for creating Avionic infrastructure within the Odisha region is emphasized by using the mathematical logic tool on a case study problem. In this case study, the first stage D1 has two options, either construct or not construct new airports with utilizing the budgeted allot money. Each option's outcome probability, conditional value and expected outcome value are determined by applying arithmetic and logical calculations to next two stages D2 and D3. The expected value and percentage of returns are mentioned in the decision trees designed in Section 3. The nodes of the decision tree are stages or chance nodes and the arc lines' labels are mentioned from the appropriate expressions written in the decision tree and chance nodes table mentioned in Section 4.
\end{abstract}

\section{Keywords}

Multistage Decision Making, Infrastructure Development

\section{Introduction}

Multistage decision making within multiple options and action plans is a study in the Operational Research using optimization techniques. The corporal or government administrations also use this type of decision making procedure 
before investing funds and resources in their ministerial task forces. The Indian state Odisha is rich with technically educated manpower, minerals like Iron, Aluminum, metallurgy industries, electrical power plant coal and water resources and the central and Odisha state governing institutions have recently initiated to expand the avionic industry infrastructure in the uniformly distributed urban regions in Odisha state.

Adequate energy resource full-filled states within the nation India are some ways depending on avionic fleet and crew sources of the central government administration for quick transportation of their state passengers and materials. The transportation ministry, civil aviation ministry and industry ministry are looking and extending the similar aviation facilities for people of Odisha state to utilize their available natural resources and planning to draw requisite mineral resources for fulfilling the need of Odisha state aviation infrastructure establishment. There are some Indian states, having neither Aluminum nor Iron minerals but have a number of airports and infrastructures for oil refineries and developing their state industries with the imported electronics and electrical instruments from abroad. However, the mentioned resource full state Odisha has to develop its state industries utilizing the imported electronics instruments through its two national airports and five domestic airports under construction by the engineering institutions in Odisha for providing facilities to carry on business with low cost and quick airways transportation of materials.

In the research paper [1], the authors published a proposed planning to expand airways transportation facility within Odisha state airports and bring the notice of Odisha administration for constructing necessary infrastructure to maintain the newly built airports for multipurpose use. In the research paper [2], the authors studied the necessary infrastructure establishment modernization at Indian airports for facilitating aircraft component assembly and manufacturing at the existing and to be constructed new airports. The newly built airports in Odisha will not only provide facility to passengers and trainee engineers with low cost quick transportation facilities such as importing materials and support industrial tour to trainee engineers, also support the service aircraft components manufacture engineering workshop facility to assemble and fabricate the aircraft structures within Odisha for the services of the nation. In the research paper [3] the authors studied the linear program problem concerning aircraft, airport and crew schedule for low cost transportation. The background for such a study is the railways, and roadways maintenance materials are costly than the maintenance of aircraft and airports. The present days' administration should realize this truth and make necessary decision to invest a proportional quantity of energy resource for the escaping from acute shortage of locomotive vehicle resource energy.

In the present paper, we emphasize a logical calculation in the form of case study to convince the Odisha Avionic developers (OAD) should invest quantity of money as value of processing Aluminum, alloy metallic engines, Rubber tube 
tires and polymers for the manufacture and assemble the aircraft parts at the location of existing Odisha airports and the new airports construction site within Odisha.

\section{Case Study}

Odisha Avionic developer (OAD) considering whether to conduct a sequence of action plans during the maintenance construction of newly built airports in Odisha to enhance Odisha avionic infrastructure development. All the action plans are mentioned in the communicated email to the secretary government of Odisha. In this paper, a few action plans are discussed. If the OAD construct and execute all related action plans, its value would be $\$ 600$ million with 65\% chances of growth. They can construct two new airports one at Dhamara and another at Rasgovindpur for develop exiting Odisha state airports and balance the atmospheric air pressure and air humidity temperature climatic environment. The probability of success in the state infrastructure growth and expected returns are mentioned in Table 1.

Table 1. Odisha airports initial data.

\begin{tabular}{ccccc}
\hline \multirow{2}{*}{ Outcome } & \multicolumn{2}{c}{ New Airport maintenance construction } & \multicolumn{2}{c}{ Existing Airport Operation } \\
\cline { 2 - 5 } & $\begin{array}{c}\text { Growth } \\
\text { Probability }\end{array}$ & $\begin{array}{c}\text { Expected Revenue } \\
\text { on million dollar }\end{array}$ & $\begin{array}{c}\text { Growth } \\
\text { Probability }\end{array}$ & $\begin{array}{c}\text { Expected Revenue } \\
\text { on million dollar }\end{array}$ \\
\hline Success & 0.75 & 800 & 0.85 & 700 \\
Failure & 0.25 & 200 & 0.15 & 350 \\
\hline
\end{tabular}

If the $\mathrm{OAD}$ does construct new airports, they can use the $\$ 600$ million to modernize the existing avionic fleet operation. This would result in a return of either $5 \%$ or $8 \%$ percent on the sum invested with probabilities 0.45 and 0.55 . This action of $\mathrm{OAD}$ also provides employment to $10 \%$ engineers in the state. Assume that all costs and revenue have been discounted to their present values. The following decision tree (Figure 1) is constructed for solving the problem by analyzing courses of actions. By applying an appropriate decision criterion recommend the OAD should go in for the construct new airports at Dhamara, and Rasgovindpur.

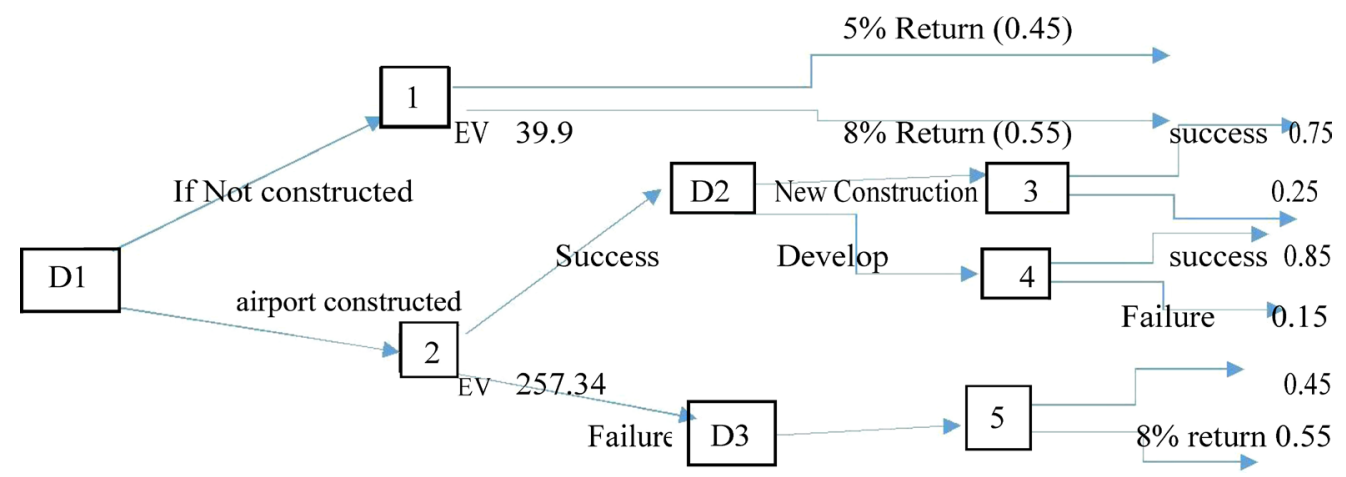

Figure 1. The decision tree. 


\section{The Decision Tree Description}

In the above designed decision tree, the node D1 is a decision stage that has two options either construct or not construct. Not constructed option line is connected to chance node 1 . The chance node 2 has two outcomes. The chance node 1 , outcome indicates expected value $5 \%$ return with probability $0.45 \%$ and the other outcome indicates $8 \%$ with probability $0.55 \%$ return.

The airport construction decision option or the chance node 2 implies two options namely success and failure. The success option arc connects to node stage D2 and failure labeled option arc connects to node stage D3. The D2 stage has two chance nodes 3 and 4 . The arc connecting stage D2 to chance node 3, labeled as new airport construction and its success is $0.75 \%$ and failure is $0.25 \%$.

The arc connecting node stage D2 to node 4 is labeled as develop existing infrastructure and its success probability is $0.85 \%$ and failure probability is $0.15 \%$.

The decision stage D 3 connects chance node 5 with the label modernize. It has two outcomes, one outcome is $5 \%$ return after investment and probability is $0.45 \%$. The other outcome is $8 \%$ and probability is $0.55 \%$.

The decision data is summarized and mentioned in following Table 2.

\section{Inference}

1) If new airports are to be constructed the expected value is 650 million dol-

Table 2. Evaluation of OAD Decision tree and chance nodes.

\begin{tabular}{|c|c|c|c|c|}
\hline Decision attributes & Outcome & Probability & $\begin{array}{l}\text { Conditional value } \\
\text { in million dollar }\end{array}$ & $\begin{array}{l}\text { Expected value in } \\
\text { million dollar }\end{array}$ \\
\hline \multirow[t]{2}{*}{ D3 (i) Modernize } & $5 \%$ of return & 0.45 & $600 \times 0.05=30$ & 13.5 \\
\hline & $8 \%$ of return & 0.55 & $600 \times 0.08=48$ & 26.4 \\
\hline \multirow[t]{3}{*}{ D2 (i) New Airport construct } & Success & 0.75 & 800 & 600 \\
\hline & Failure & 0.25 & 200 & 50 \\
\hline & & & & 650 \\
\hline (ii) Develop Existing & Success & 0.85 & 700 & 595 \\
\hline \multirow[t]{2}{*}{ Infra } & Failure & 0.15 & 350 & 52.5 \\
\hline & & & & 647.5 \\
\hline \multirow[t]{3}{*}{ D1 (i) if not constructed } & $5 \%$ of returns & 0.45 & $600 \times 0.05=30$ & 13.5 \\
\hline & $8 \%$ of returns & 0.55 & $600 \times 0.08=48$ & 26.4 \\
\hline & & & & 39.9 \\
\hline \multirow[t]{5}{*}{ (ii) If constructed } & Success & 0.65 & $650+647.5$ & 843.375 \\
\hline & Failure & 0.35 & 39.9 & 13.965 \\
\hline & & & & 857.340 \\
\hline & & & & (-) 600.000 \\
\hline & & & & 257.34 \\
\hline
\end{tabular}


lars and the existing Avionic fleet is to be developed, the expected value is 647.5 million dollars. Total value is 1297.5 million dollars and success probability is $0.65 \%$ the updated expected value is 857.340 million dollars. If invested value is 600 million dollar is to be subtracted, the net expected value is 257.34 million dollars.

2) If only existing avionic fleet is to be developed and new airport is to be constructed the invested 600 million dollars will be subtracted from 647.5 million dollars which will yield 47.5 million dollar if the success is $100 \%$.

3) The Existing avionic fleet development is only possible if the aircrafts are manufactured within the state airports with utilizing state engineering manpower and mineral resources. It is possible to build new airports and expand existing airport infrastructure establishment and machine workshops. So new airports with modernizing equipment facility can develop avionic fleet.

\section{Conclusion}

The quantity of dollars mentioned in the case study is a virtual quantity. But the Odisha state industries transacting minerals and resources concerned to manufacture industry products such as Iron, Aluminum, Cuppers wires, rubber tires, alloy metallic engines and in these mater's manufacturing phase, processed petrochemicals are valued real millions of dollar invested in each year. The mineral query such as Iron ore, Bauxite ore and Coal mine operating robots, ore transporter trucks operating from query site to plant site, product minerals from plant to warehouse site, are consuming $60 \%$ of net petroleum, diesel and kerosene quantity imported from abroad seaports to state Odisha. The remaining $40 \%$ of imported refined petrochemical to Odisha Indian Oil stores are utilized in other domestic industries and agriculture food process purposes. If two airports one at Dhamara and other at Rasgovindpur in Odisha are to be constructed, it will consume at most $0.01 \%$ of imported petrochemicals during the construction phase and completion after aircraft operational phase. The $80 \%$ of imported mineral oil to Odisha are utilized in metal extraction and the industry product maters transportation, and $80 \%$ of industry products are not used in the service or building infrastructure within Odisha.

\section{Conflicts of Interest}

The authors declare no conflicts of interest regarding the publication of this paper.

\section{References}

[1] Das, L.N., Parhi, S.K. and Mallick, C.R. (2017) Aircraft Component Manufacturing Machines Operation Schedule Usable Informative Text. International Journal of Engineering Research and Application, 7, 20-22.

[2] Das, L. and Singari, R.M. (2017) Multistage Advanced Tasking for Manufacture of Aircrafts in Indian Airports Utilising Industry Machineries. 2nd International Conference on Advanced Production and Industrial Engineering ICAPIE-2017, Delhi, 6-7 December 2017. 
[3] Das, L., Sahu, M. and Venue, R. (2017) Aircraft Crew and Airport Schedule for Low Cost Transport. 7 th International Conference on Soft Computing for Problem Solving SocProS 2017, Bhubaneswar, 23-24 December 2017. 